PEREIRA, A.V.; OTTO, R.F.; REGHIN, M.Y. Respostas do feijão-vagem cultivado sob proteção com agrotêxtil em duas densidades de plantas. Horticultura Brasileira, Brasília, v. 21, n. 3, p. 564-569, julho-setembro 2003.

\title{
Respostas do feijão-vagem cultivado sob proteção com agrotêxtil em duas densidades de plantas
}

\author{
Adalberto Vitor Pereira; Rosana F. Otto; Marie Y. Reghin \\ UEPG, Depto. Fitotecnia e Fitossanidade, Praça Santos Andrade s/n, 84010-790 Ponta Grossa-PR; E-mail: rfotto@uepg.br reghin@convoy.com.br
}

\begin{abstract}
RESUMO
Estudou-se o efeito da proteção com agrotêxtil e densidades de plantas sobre a produtividade de duas cultivares de feijão-vagem de porte determinado. $\mathrm{O}$ ensaio foi conduzido na área experimental da UEPG, Ponta Grossa. Utilizou-se o delineamento experimental inteiramente casualizado em esquema fatorial $2 \times 2 \times 2$ (cultivares $\times$ proteção $\mathrm{x}$ densidade), com 4 repetições. As cultivares utilizadas foram Turmalina e Coralina, semeadas em março de 2000 (outono) em duas densidades de plantas $\left(6,6\right.$ e $\left.3,3 \mathrm{pl} \mathrm{m}^{-1}\right)$, sob proteção com agrotêxtil (PP) e em ambiente natural (AN). Avaliou-se a produção precoce, a produtividade, o número de vagens por planta e o peso médio das vagens. Como parâmetro climático, determinou-se a amplitude das modificações das temperaturas do ar (Tar) e do solo (Ts) sob PP e AN. A proteção das plantas com agrotêxtil e a variação de densidades não influenciaram na precocidade da colheita. Entretanto, o uso do agrotêxtil resultou em aumento da produtividade para 'Turmalina' devido ao maior número de vagens por planta comparado ao AN. Para a cultivar Coralina não houve diferença na produtividade entre os cultivos em AN e PP. A densidade de plantas não apresentou diferença na produtividade para 'Turmalina'. Por outro lado, a cultivar 'Coralina' foi mais produtiva quando cultivada em densidade de $3,3 \mathrm{pl} \mathrm{m}^{-1}$, em relação à densidade de $6,6 \mathrm{pl} \mathrm{m}^{-1}$. Quando cultivadas com $3,3 \mathrm{pl} \mathrm{m}^{-1}$, a 'Coralina' foi mais produtiva que a 'Turmalina', porém em densidade de $6,6 \mathrm{pl} \mathrm{m}^{-1}$ não houve diferença entre as cultivares. As temperaturas do ar e do solo foram maiores sob PP em relação ao AN, durante todo o ciclo da cultura, com diferenças médias entre ambientes de 2,63 e $1,97^{\circ} \mathrm{C}$, respectivamente para Tar e Ts. Os valores da diferença entre PP e AN, para Tar e Ts, foram maiores na fase inicial da cultura, diminuindo com o crescimento do feijão-vagem.
\end{abstract}

Palavras-chave: Phaseolus vulgaris L.; cultivo protegido, 'não tecido' de polipropileno.

\begin{abstract}
Response of snap beans cultivated in two plant densities under nonwowen protection in Brazil

The effect of nonwowen polypropylene protection condition and plant density on the yield of two cultivars of snap beans was evaluated. The current work was carried out at an experimental area of the Universidade Estadual de Ponta Grossa, Paraná State, Brazil. The experimental design was a completely randomized in split plots $2 \times 2 \times 2$ (cultivars $\mathrm{x}$ protection $\mathrm{x}$ plant density), with four replications. The cultivars Turmalina and Coralina were sown in March (autumn), 2000, in two plant densities $\left(6.6\right.$ and $\left.3.3 \mathrm{pl} \mathrm{m}^{-1}\right)$ under nonwowen protection (PP) and natural environment (AN). Early yield, total yield, number and weight of pods were evaluated. The air (Tar) and soil temperature amplitudes (Ts) under PP and AN were also evaluated. Nonwoven protection and plant density did not influence the early yield. However, the use of nonwoven protection increased yield of 'Turmalina' as a result of higher number of pods per plant, compared with AN. There was no difference between PP and AN on yield of 'Coralina'. The plant density did not influence yield response of 'Turmalina'. On the other hand, 'Coralina' was more productive when cultivated under plant density of 3,3 $\mathrm{pl} \mathrm{m}^{-1}$, when compared to $6,6 \mathrm{pl}$ $\mathrm{m}^{-1}$. 'Coralina' was more productive than 'Turmalina' when cultivated under $3,3 \mathrm{pl} \mathrm{m}^{-1}$, however without differences between cultivars under $6,6 \mathrm{pl} \mathrm{m}-1$. Air and soil temperature were higher under PP compared to AN, during the whole cycle of the culture, with medium differences between $\mathrm{PP}$ and $\mathrm{AN}$ of 2,63 and $1,97^{\circ} \mathrm{C}$, respectively for Tar and Ts. The difference between PP and AN, for Tar and Ts, was higher at the beginning of plant growing and decreased with the development of snap bean.
\end{abstract}

Keywords: Phaseolus vulgaris L., protected cultivation, nonwoven polypropylene.

(Recebido para publicação em 11 de dezembro de 2002 e aceito em 18 de junho de 2003)

$\mathrm{D}$ entre as hortaliças com maior volume de comercialização na CEASA-PR, encontra-se o feijão-vagem, que atinge cerca de 6000 toneladas por ano. A comercialização é feita durante todos os meses do ano, sendo julho, agosto, setembro e outubro os meses de menor oferta do produto. A produção destina-se ao consumo in natura, sendo pequeno o volume industrializado.

O feijão-vagem (Phaseolus vulgaris) pertence à mesma família e espécie botânica do feijão comum, diferindo por ser uma hortaliça que fornece vagens imaturas (Filgueira, 2000). Apesar de não ser rica em proteínas e calorias como os grãos secos, é rica em vitaminas e sais mineras, que faltam na maioria dos alimentos (Jassen, 1992, citado por Peixoto et al., 1997).

As cultivares de crescimento determinado, embora menos produtivas que as de hábito trepador, têm a vantagem de não necessitar de tutoramento e possibilitar a mecanização da lavoura, condições que podem aumentar a rentabilidade do produtor (Peixoto et al., 1997). Outra vantagem é a possibilidade de se efetuar uma única colheita, com o arranquio das plantas no campo e a posterior separação das vagens (Peixoto $e t$ al., 1997; Filgueira, 2000).

Da mesma forma que o feijoeiro comum, o feijão-vagem é cultura de ampla adaptação a climas quentes e amenos, dentro de uma faixa térmica de 18 a $30^{\circ} \mathrm{C}$ (Filgueira, 2000), no entanto, é intolerante a fatores extremos do ambiente. Temperaturas elevadas ocasionam significativa redução da produtividade na fase vegetativa inicial, podendo causar morte das plântulas e, conseqüentemente, redução do estande. $\mathrm{Na}$ fase de intenso crescimento vegetativo, 
o calor excessivo aumenta a fotorespiração, reduzindo a taxa de crescimento das plantas (Mariot, 2000). Durante a fase reprodutiva, altas temperaturas exercem influência sobre o aborto de flores, vingamento e retenção final das vagens (Portes, 1988 citado por Andrade, 1998). No período entre a diferenciação dos botões florais até o enchimento dos grãos nas vagens, as altas temperaturas reduzem o número de vagens por planta, devido à esterilização do grão de pólen e, conseqüentemente, a queda das flores (Mariot, 2000). Assim como para temperaturas excessivas, o feijão-vagem é uma das hortaliças mais intolerantes ao frio e a geadas (Filgueira, 2000). As baixas temperaturas, quando ocorrem logo após a semeadura, podem impedir, reduzir ou atrasar a germinação das sementes e a emergência das plântulas, resultando em baixa população e baixa produtividade. Durante o crescimento vegetativo reduzem a altura das plantas e ramos, diminuindo a produção de vagens por planta (Portes, 1996 citado por Andrade 1998).

Temperaturas inferiores a $15^{\circ} \mathrm{C}$ inviabilizam o funcionamento normal dos órgãos reprodutivos. Na faixa de 2 a $10^{\circ} \mathrm{C}$, as plantas reduzem a produção de biomassa e retardam o desenvolvimento, devido às alterações metabólicas provocadas pelo esfriamento. $\mathrm{O}$ esfriamento do solo também pode facilitar o apodrecimento das sementes promovendo queda no estande (Filgueira, 2000). A ocorrência de geadas causa injúrias por congelamento nos tecidos, sendo prejudicial em qualquer estádio de desenvolvimento das plantas (Mariot, 2000). Em localidades onde as condições climáticas não permitem o plantio de feijão-vagem durante o ano todo em condições naturais de campo, o cultivo é realizado sob proteção. Na região sul do Brasil, além das estufas plásticas não climatizadas, está sendo utilizado o agrotêxtil que, em alguns países da Europa já é usado na agricultura para proteção de plantas desde o início dos anos 80. No Brasil, os trabalhos de pesquisa com agrotêxtil iniciaram-se no final da década de 90, na região dos Campos Gerais, no estado do Paraná, onde hoje é utilizado por produtores de hortaliças para proteção de cultivos.
Algumas das vantagens da utilização do agrotêxtil em cultivo protegido é a possibilidade de sua colocação e retirada em qualquer fase de desenvolvimento da cultura e a possibilidade de ser colocado diretamente sobre as plantas ou solo sem a necessidade de estruturas de sustentação.

Para culturas como alface (Fuello et al., 1993; Otto et al., 2001), mandioquinha salsa (Reghin et al., 2000), morango (Otto et al., 2000a; Otto et al., 2000b), pimentão (Pereira et al., 2001), beterraba, espinafre (Otto et al., 2000c) e couve-chinesa (Otto et al., 2000c; Colturato et al., 2001), a utilização do agrotêxtil como proteção de plantas tem apresentado bons resultados, mostrando como vantagens de sua utilização, a precocidade de colheita, aumento da produção, barreira física contra geadas, melhoria da qualidade do produto final, melhora da sanidade, manutenção da umidade do solo, precocidade e qualidade na produção de mudas, entre outras.

Como em qualquer sistema utilizado no cultivo protegido, o uso do agrotêxtil também modifica o ambiente sob proteção. As variações das temperaturas do ar e do solo constituem dois componentes importantes do balanço de energia formado sob o agrotêxtil (Otto et al, 2000c). Mourão (1997) encontrou aumento da temperatura média do ar embaixo da proteção com agrotêxtil de 1 a $2^{\circ} \mathrm{C}$ e do solo a $10 \mathrm{~cm}$ de profundidade, de 2 a $3^{\circ} \mathrm{C}$. Faouzi et al. (1993) observaram aumento na temperatura do ar sob o polipropileno de 1,4 a $4,3^{\circ} \mathrm{C}$ e Mansour \& Hemphil (1987) obtiveram valores em torno de $2^{\circ} \mathrm{C}$ em relação ao ambiente natural.

Além das condições climáticas, a produtividade da cultura do feijão pode aumentar com o uso de algumas práticas culturais, como população de plantas (Drake \& Silbernagel, 1982). A distribuição adequada de plantas tem efeito sobre a incidência de plantas daninhas e pode representar estratégia importante para a utilização mais eficiente de alguns fatores de produção, como radiação, nutrientes (Silva, 1996) e água. Durante a fase reprodutiva, a radiação é um dos principais fatores de competição entre as plantas, período em que a planta atinge o máximo de área foliar (Brandes, 1971, citado por Araújo, 1998). O aumento demasiado do número de plantas pode reduzir a intensidade da cor e a uniformidade das vagens, resultando em redução na qualidade sensorial (Drake \& Silbernagel, 1982). Ademais, tende a ocorrer mais acamamento, fazendo com que as vagens toquem o solo, depreciando-as e, conseqüentemente, reduzindo o valor comercial. A alta população de plantas também favorece a ocorrência de doenças e pragas, devido ao microclima propício formado nesta situação (Lollato, 2000).

A escolha da população deverá levar em consideração informações como época de semeadura, região (altitude e latitude), histórico de doenças na área (principalmente fungos do gênero Fusarium, Rhizoctonia e Sclerotinia), hábito de crescimento (Dourado Neto \& Fancelli, 2000), cultivar e fertilidade do solo (Almeida \& Canéchio Filho, 1974).

Os espaçamentos recomendados para o cultivo do feijão-vagem anão encontram-se numa faixa de 7 a $30 \mathrm{~cm}$ entre plantas e 45 a $90 \mathrm{~cm}$ entre linhas. De acordo com Adsule et al. (1998), o espaçamento a ser recomendado é 7,7 a $10 \mathrm{~cm}$ entre plantas por 45 a $90 \mathrm{~cm}$ entre linhas, porém alguns produtores utilizam 20 a $30 \mathrm{~cm}$ por 60 a $95 \mathrm{~cm}$. Para Filgueira (2000), o espaçamento ideal é 15 x $50 \mathrm{~cm}$ entre plantas e linhas. No entanto, para cada cultivar existe uma faixa ótima de população onde as plantas aproveitam o máximo de radiação, água e nutrientes, proporcionando aumento da produtividade, sendo que tal produtividade deve estar associada à facilidade de execução dos tratos culturais, colheita e economia de insumos (Lollato, 2000).

O presente trabalho objetivou estudar o efeito do agrotêxtil sobre a produção de duas cultivares de feijão-vagem de crescimento determinado, cultivadas em duas densidades de plantas e monitorar as modificações microclimáticas da proteção com agrotêxtil na região de Ponta Grossa.

\section{MATERIAL E MÉTODOS}

O experimento foi conduzido no ano de 2000, em campo da UEPG, situada 
Tabela 1. Produtividade $\left(\mathrm{t} \mathrm{ha}^{-1}\right)$, número de vagens por planta e peso médio das vagens $(\mathrm{g})$ de duas cultivares de feijão-vagem cultivadas sob proteção com agrotêxtil e em ambiente natural (AN). Ponta Grossa, UEPG, 2000.

\begin{tabular}{|c|c|c|c|c|c|c|c|}
\hline \multirow{2}{*}{ Cultivar } & \multicolumn{2}{|c|}{ Produtividade $\left(\mathrm{t} \mathrm{ha}^{-1}\right)$} & \multicolumn{2}{|c|}{ No de vagens/planta } & \multicolumn{3}{|c|}{ Peso médio (g) } \\
\hline & Agrotêxtil & AN & Agrotêxtil & AN & Agrotêxtil & AN & Média \\
\hline Turmalina & $16,2 \mathrm{~A}^{*}{ }^{*}$ & $9,9 \mathrm{~B} \mathrm{~b}$ & $21,0 \mathrm{~A} \mathrm{a}$ & $14,0 \mathrm{~B} \mathrm{~b}$ & 8,5 & 8,0 & $8,3 \mathrm{a}$ \\
\hline Coralina & $15,0 \mathrm{~A} \mathrm{a}$ & $14,0 \mathrm{~A} \mathrm{a}$ & $20,0 \mathrm{~A} \mathrm{a}$ & $18,0 \mathrm{~A} \mathrm{a}$ & 7,8 & 7,8 & $7,8 \mathrm{~b}$ \\
\hline Média & & & & & $8,2 A^{*}$ & $7,9 \mathrm{~A}$ & \\
\hline C. V. (\%) & \multicolumn{2}{|c|}{21,2} & \multicolumn{2}{|c|}{4,5} & & 4,5 & \\
\hline
\end{tabular}

*médias seguidas da mesma letra maiúscula em linha e minúscula na coluna não diferem entre si pelo teste de Tukey a 5\% de probabilidade. C.V. (\%) - Coeficiente de variação.

na latitude $25^{\circ} 05^{\prime}$ Sul e longitude $05^{\circ} 33^{\prime}$ Oeste e altitude média de $950 \mathrm{~m}$. O solo foi classificado como CAMBISSOLO HÁPLICO Distrófico de textura argilosa. O clima do município de Ponta Grossa é classificado, segundo o Sistema de Köppen, como $\mathrm{Cfb}$ ou temperado propriamente dito; com temperatura média do mês mais frio abaixo de $18^{\circ} \mathrm{C}$ (mesotérmico), com verão fresco, temperatura média do mês mais quente abaixo de $22^{\circ} \mathrm{C}$ e sem estação seca definida. A precipitação e temperatura média anual são $1700 \mathrm{~mm}$ e $20^{\circ} \mathrm{C}$, respectivamente.

Utilizou-se o delineamento inteiramente casualizado, distribuído em esquema fatorial $2 \times 2 \times 2$ (cultivares $\times$ sistemas de proteção $\mathrm{x}$ espaçamentos) com 4 repetições. As cultivares de feijão-vagem utilizadas foram Turmalina e Coralina, com cultivo em ambiente natural (AN) e sob agrotêxtil (PP) e densidade de 3,3 e 6,6 $\mathrm{pl} \mathrm{m}^{-1}$.

As cultivares Turmalina e Coralina são de porte determinado e com ciclo médio de 35 a 50 dias da semeadura à floração, e de 55 a 70 dias da semeadura ao início da colheita. O número de colheitas varia de duas a quatro, com três a cinco dias de intervalo, apresentando produtividade total de 8 a $15 \mathrm{tha}^{-1}$ de vagens, no ponto comercial (EMATER,1997). Possuem teor de fibra em torno de 1,17 e $1,37 \%$ para 'Coralina' e 'Turmalina', respectivamente (Oliveira et al., 2001).

A semeadura foi realizada manualmente em 18/03/00 em sulcos distanciados de $0,50 \mathrm{~m}$. Os espaçamentos entre plantas foram 15 e $30 \mathrm{~cm}$, correspondendo às densidades de 6,6 e 3,3 $\mathrm{pl} \mathrm{m}^{-1}$, respectivamente. Cada unidade experimental era composta de 3 linhas com 10 plantas por linha, perfazendo um total de 30 plantas por parcela.
$\mathrm{O}$ agrotêxtil de cor branca com gramatura de $20 \mathrm{~g} \mathrm{~m}^{-2}$ foi colocado 10 dias após a semeadura (DAS) e fixado lateralmente com pedras para os tratamentos com cultivo protegido. As plantas permaneceram protegidas com agrotêxtil durante todo período em que a cultura ficou a campo, sendo retirado apenas para realização de tratos culturais.

A adubação química foi realizada no momento da semeadura com $300 \mathrm{~kg} \mathrm{ha}^{-1}$ de 4-14-8, incorporado no sulco de plantio. Realizou-se adubação nitrogenada em cobertura com uréia a $100 \mathrm{~kg} \mathrm{ha}^{-1}$ aos 27 DAS e adubação via foliar com magnésio $\left(1 \mathrm{~L} \mathrm{ha}^{-1}\right)$ aos 35 DAS.

As irrigações foram realizadas por aspersão e as capinas feitas aos 15; 27 e 33 DAS para evitar a competição das plantas daninhas com a cultura. Aos 65 DAS aplicou-se Thiametoxan $(200 \mathrm{~g}$ em 100L) quando os danos de vaquinha (Diabrotica speciosa) atingiram o nível de controle. Nesta data também aplicouse Propiconazole na proporção de $40 \mathrm{~g}$ em 100 L de água, para o controle de oídio (Oidium sp.). Aos 72 DAS fez-se outra aplicação de fungicida para controle de oídio, ferrugem (Uromyces sp.) e antracnose (Colletotricum sp.), com Tebuconazole $\left(0,5 \mathrm{~L} \mathrm{ha}^{-1}\right)$ e Fentin hydroxyde $\left(0,3 \mathrm{~L} \mathrm{ha}^{-1}\right)$. As aplicações foram realizadas com pulverizador costal com bico tipo leque.

Em cada parcela, colheu-se as vagens das 8 plantas centrais da linha central, aos 62; 68; 75; 84 e 94 DAS. Avaliou-se a produção precoce através do peso total das vagens colhidas entre 62 e 68 DAS, a produtividade, o número de vagens por planta e o peso médio das vagens.
Para a coleta dos dados microclimáticos instalou-se sensores de temperatura do ar e do solo, aos 13 DAS. Os sensores de temperatura do ar e do solo foram colocados a $15 \mathrm{~cm}$ acima da superfície do solo e a $10 \mathrm{~cm}$ de profundidade, sob proteção com agrotêxtil e em ambiente natural. Todos os sensores foram conectados ao Datalloger CR 23X - Campbell Scientific, programado para realizar leituras a cada minuto e médias a cada hora, durante todo o ciclo da cultura. Os dados obtidos no ensaio foram submetidos à análise de variância, utilizando-se para comparação de médias o teste de Tukey, ao nível de 5\% de probabilidade.

\section{RESULTADOS E DISCUSSÃO}

\section{Produção}

A colheita das plantas iniciou-se aos 62 DAS, não ocorrendo diferença entre os tratamentos avaliados para precocidade. Não houve interação significativa entre proteção $\mathrm{x}$ densidade de plantas e proteção $\mathrm{x}$ densidade de plantas $\mathrm{x}$ cultivares.

Para a produção total de vagens frescas ocorreu interação entre cultivares $\mathrm{x}$ proteção e cultivares $\mathrm{x}$ densidade. $\mathrm{Na}$ combinação cultivares $\mathrm{x}$ proteção, a 'Turmalina' produziu 39\% a mais quando cultivada sob proteção com agrotêxtil comparada à produção em ambiente natural (Tabela 1). No entanto, a 'Coralina' não apresentou diferença entre os dois sistemas de cultivo. Não houve diferença na produção entre as cultivares quando cultivadas sob agrotêxtil. Em ambiente natural, a 'Coralina' superou em $29 \%$ a produção da 'Turmalina' (Tabela 1), que por sua vez teve produ- 
Tabela 2. Produtividade $\left(\mathrm{t} \mathrm{ha}^{-1}\right)$, número de vagens por planta e peso médio das vagens $(\mathrm{g})$ de duas cultivares de feijão-vagem cultivadas em duas densidades de plantas $\left(6,6 \mathrm{e} \mathrm{3,3} \mathrm{pl} \mathrm{m}^{-1}\right)$. Ponta Grossa, UEPG, 2000.

\begin{tabular}{|c|c|c|c|c|c|c|c|c|}
\hline \multirow{2}{*}{ Cultivar } & \multicolumn{2}{|c|}{ Produtividade $\left(\mathrm{t} \mathrm{ha}^{-1}\right)$} & \multicolumn{3}{|c|}{ No de vagens/planta } & \multicolumn{3}{|c|}{ Peso médio (g) } \\
\hline & $6,6 \mathrm{pl} \mathrm{m}^{-1}$ & $3,3 \mathrm{pl} \mathrm{m}^{-1}$ & $6,6 \mathrm{pl} \mathrm{m}^{-1}$ & $3,3 \mathrm{pl} \mathrm{m}^{-1}$ & Média & $6,6 \mathrm{pl} \mathrm{m}^{-1}$ & $3,3 \mathrm{pl} \mathrm{m}^{-1}$ & Média \\
\hline Turmalina & $12,5 \mathrm{~A} \mathrm{a}^{*}$ & $13,6 \mathrm{Ab}$ & 13,0 & 22,0 & $17,5 \mathrm{a}$ & 8,0 & 8,5 & $8,3 a$ \\
\hline Coralina & $11,3 \mathrm{~B} \mathrm{a}$ & $17,7 \mathrm{~A} \mathrm{a}$ & 17,0 & 21,0 & $19,0 \mathrm{a}$ & 7,7 & 8,0 & $7,8 \mathrm{~b}$ \\
\hline Média & & & $15,0 B^{*}$ & $22,0 \mathrm{~A}$ & & $7,8 \mathrm{~B}$ & $8,2 \mathrm{~A}$ & \\
\hline C. V. $(\%)$ & \multicolumn{2}{|c|}{21,2} & & 19,4 & & & 4,5 & \\
\hline
\end{tabular}

*médias seguidas da mesma letra maiúscula em linha e minúscula na coluna não diferem entre si pelo teste de Tukey a 5\% de probabilidade. C.V. (\%) - Coeficiente de variação.

tividade abaixo da média nacional (13 t ha $^{-1}$ ), segundo Peixoto et al. (1997). A redução da produtividade da 'Turmalina' cultivada a campo, deve-se possivelmente à época de plantio (outono), pois as temperaturas tendem a diminuir com o passar dos dias afetando o metabolismo das plantas que não são adaptadas a essa região, como é o caso da 'Turmalina'.

A maior produção da 'Turmalina' sob agrotêxtil é explicada pelo número de vagens por planta (Tabela 1). As plantas da 'Turmalina', quando protegidas, apresentaram 7 vagens por planta a mais que em ambiente natural. Para 'Coralina', as plantas protegidas com agrotêxtil não diferiram quanto ao número de vagens das plantas cultivadas em ambiente natural (Tabela 1). As cultivares também não diferiram entre si quanto ao número de vagens por planta, quando cultivadas sob proteção. Por outro lado, em ambiente natural, as plantas da 'Coralina' formaram 4 vagens por planta a mais que a 'Turmalina' (Tabela 1). Estes resultados indicam que a 'Turmalina', devido a sua sensibilidade às baixas temperaturas, responde melhor à proteção com agrotêxtil quando comparada à 'Coralina', uma vez que a 'Turmalina' foi mais produtiva sob agrotêxtil, devido ao maior número de vagens formadas. Este resultado pode estar relacionado ao microclima formado sob a proteção, que propiciou a emissão de maior número de flores por planta ou, possivelmente, a proteção reduziu a taxa de abscisão dos órgãos reprodutivos. Poderia ser possível que o incremento na produtividade da 'Turmalina' sob agrotêxtil em relação ao cultivo em ambiente natural estivesse relacionado ao maior peso médio das vagens. Porém, a diferença em relação a esta característica não foi significativa entre os tratamentos (Tabela 1). Entre as cultivares, a 'Turmalina', conforme esperado, apresentou vagens com maior peso em relação à 'Coralina', sendo esta uma característica genética da cultivar.

Para a combinação entre cultivar e densidade de plantas, a produtividade da 'Turmalina' não diferiu entre as densidades, entretanto, a 'Coralina' produziu mais quando cultivada em densidade de $3,3 \mathrm{pl} \mathrm{m}^{-1}$ em relação a $6,6 \mathrm{pl} \mathrm{m}^{-1}$ (Tabela 2). Quando as cultivares foram semeadas em baixa densidade $\left(3,3 \mathrm{pl} \mathrm{m}^{-1}\right)$, a 'Coralina' foi mais produtiva que a 'Turmalina', porém em alta densidade $\left(6,6 \mathrm{pl} \mathrm{m}^{-1}\right)$ não houve diferença entre as cultivares (Tabela 2). Isto demonstra que a cultivar Coralina se adapta melhor a baixas densidades.

Apesar do menor número de plantas por área em densidade de $3,3 \mathrm{pl} \mathrm{m}^{-1}$ $\left(66.666 \mathrm{pl} \mathrm{ha}^{-1}\right)$ comparado à densidade de $6,6 \mathrm{pl} \mathrm{m}^{-1}$ (133.333 $\left.\mathrm{pl} \mathrm{ha}^{-1}\right)$, a produtividade não diferiu para a 'Turmalina' e aumentou para a 'Coralina'. Estes resultados mostraram que ambas cultivares apresentaram efeito compensador. De acordo com Lollato (2000), o feijoeiro apresenta grande capacidade de ocupação dos espaços laterais disponíveis, podendo compensar parcialmente eventuais excessos de espaçamento ou redução de densidade de plantas. Ademais, a produtividade de ambas cultivares, quando semeadas em densidade de 6,6 $\mathrm{pl} \mathrm{m}{ }^{-1}$ ficou abaixo da média nacional para cultivares de porte determinado (13 tha-1).

A densidade de $3,3 \mathrm{pl} \mathrm{m}^{-1}$ resultou em maior número e peso médio de vagens por planta, comparado à densidade de 6,6 $\mathrm{pl} \mathrm{m} \mathrm{m}^{-1}$ (Tabela 2). O aumento no número e peso de vagens compensou o menor número de plantas por hectare igualando e aumentando a produção, dentro das densidades, para 'Turmalina' e 'Coralina', respectivamente.

Os resultados de número e peso médio de vagens por planta para interação cultivar $\mathrm{x}$ densidade (Tabela 2) concordam com alguns autores. De acordo com Ramalho et al. (1978), citados por Araújo (1998), o número de vagens por planta e peso médio das vagens são os principais componentes da produção afetados pela densidade de plantas, (devido à competição por radiação, água e nutrientes) que, conseqüentemente, irão influir na produtividade. Os autores citados enfatizam que o número de vagens é o componente de produção mais afetado pela população de plantas.

\section{Modificações Microclimáticas}

A temperatura do ar sob agrotêxtil foi maior que em ambiente natural durante todo o ciclo da cultura. Os valores da diferença entre as temperaturas dos tratamentos diminuíram com o desenvolvimento da cultura (Figura 1). A diferença entre temperatura do ar sob agrotêxtil e em ambiente natural foi de $4,85^{\circ} \mathrm{C}$ aos $25 \mathrm{DAS}$, diminuindo para $3,50^{\circ} \mathrm{C}$ aos $35 \mathrm{DAS}$, fase em que iniciou o florescimento das plantas, de $1,53^{\circ} \mathrm{C}$ aos 55 DAS (enchimento das vagens) e de $1,37^{\circ} \mathrm{C}$ aos $85 \mathrm{DAS}$, fase final de produção. Em média, a temperatura do ar sob proteção com agrotêxtil foi $2,6^{\circ} \mathrm{C}$ maior que em ambiente natural, oscilando entre 0,20 e $7,31^{\circ} \mathrm{C}$. De acordo com Otto et al. (2000c), a intensidade dessas modificações depende da época do ano, do desenvolvimento da cultura e da espécie cultivada. O plantio foi realizado no início do outono e 


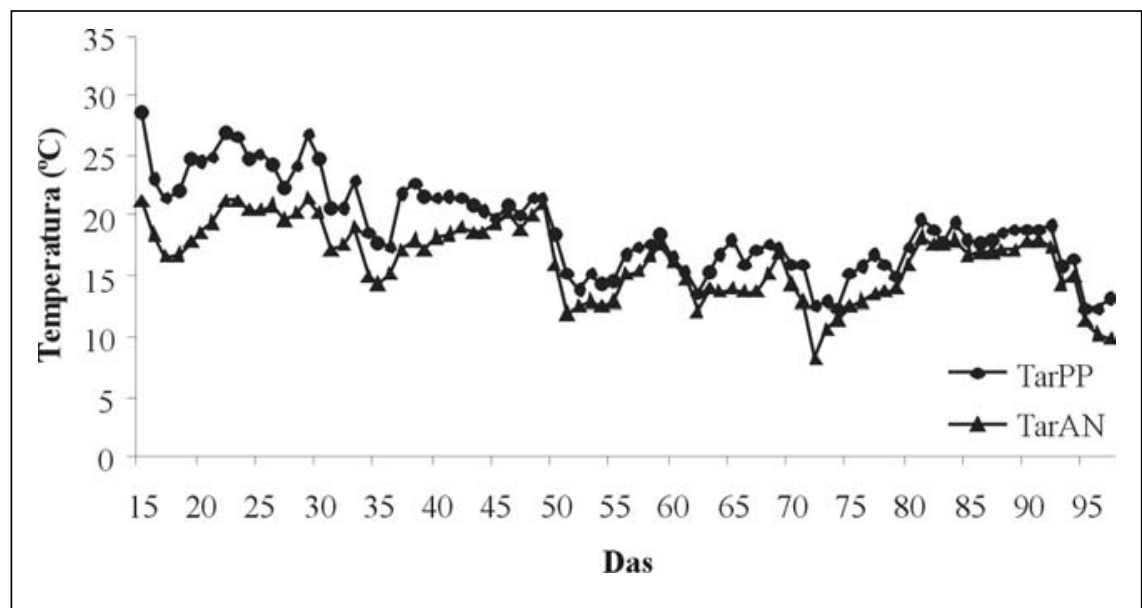

Figura 1. Temperatura média do ar $(15 \mathrm{~cm}$ de altura do solo) para os tratamentos sob agrotêxtil (TarPP) e em ambiente natural (TarAN), durante todo o ciclo da cultura do feijão-vagem. Ponta Grossa, UEPG, 2000.

$($ Das $=$ dias após a semeadura $)$

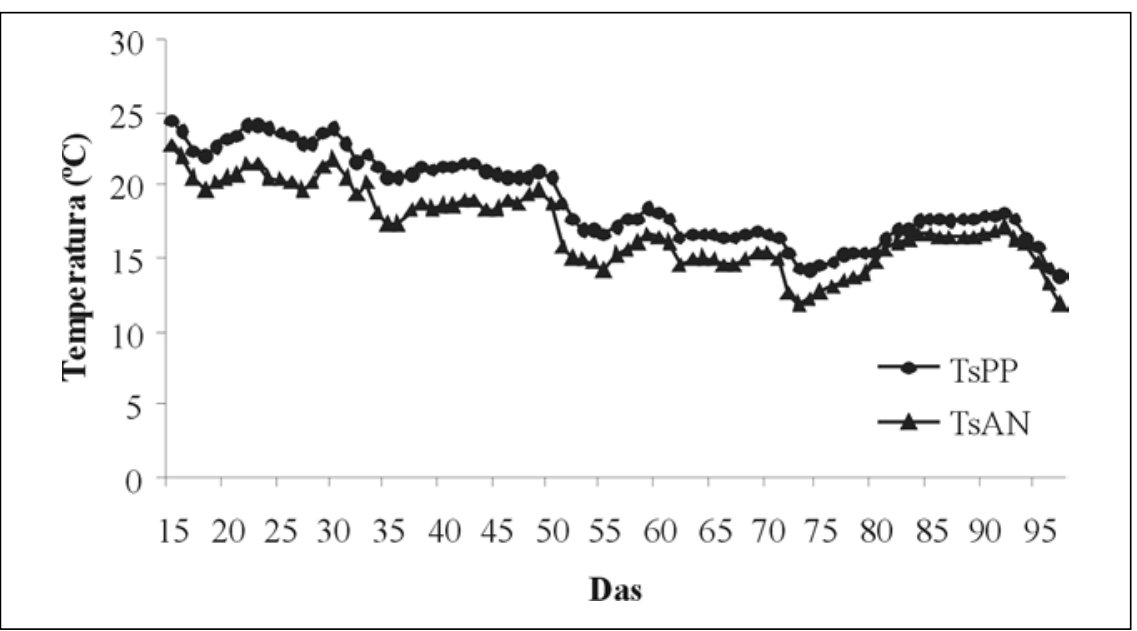

Figura 02. Temperatura média do solo (10 $\mathrm{cm}$ de profundidade) para os tratamentos sob agrotêxtil (TsPP) e em ambiente natural (TsAN), durante todo o ciclo da cultura do feijãovagem. Ponta Grossa, UEPG, 2000.

(Das $=$ dias após a semeadura)

com o passar dos dias a temperatura do ar diminuiu naturalmente. A menor temperatura registrada sob agrotêxtil durante o ciclo da cultura foi $12,26^{\circ} \mathrm{C}$ e em ambiente natural de $8,12^{\circ} \mathrm{C}$. A maior temperatura sob agrotêxtil e em ambiente natural foi 28 e $21^{\circ} \mathrm{C}$, respectivamente. Com isso, a integral térmica diária ao longo de todo o ciclo, no ambiente protegido foi mais favorável ao crescimento e desenvolvimento do feijão-vagem, em especial, para 'Turmalina'. Esses resultados concordam com Mansour \& Hemphil (1987); Faouzi et al. (1993); Mermier et al. (1995), Mourão (1997) e Otto et al. (2000c).
Para temperatura do solo, os valores sob agrotêxtil foram maiores que em ambiente natural durante todo o ciclo da cultura. De semelhante modo ao ocorrido com a temperatura do ar, os valores da diferença entre as temperaturas do solo dos tratamentos diminuíram com o desenvolvimento da cultura (Figura 2).

A proteção com agrotêxtil reduziu a perda de calor para o meio externo. A diferença máxima entre $\mathrm{PP}$ e $\mathrm{AN}$ foi de $3,3^{\circ} \mathrm{C}$ aos 24 DAS e a mínima foi de $0,58^{\circ} \mathrm{C}$ aos 94 DAS. O aumento médio da temperatura do solo a $10 \mathrm{~cm}$ de profundidade foi de $1,97^{\circ} \mathrm{C}$ com o uso do agrotêxtil, sendo coerente com os resultados encontrados por Mourão (1997) e Otto et al. (2000c).

Essas modificações na temperatura do solo e ar, decorrentes do uso da proteção, favoreceram o desenvolvimento das plantas de feijão-vagem cultivadas durante o outono na região de Ponta Grossa. De acordo com Filgueira (2000), a faixa de temperatura do ar considerada ótima para a cultura do feijãovagem é de $18-30^{\circ} \mathrm{C}$. A temperatura média registrada em ambiente natural durante o ciclo da cultura foi $16^{\circ} \mathrm{C}$, (abaixo da referida faixa) e sob proteção foi de $19^{\circ} \mathrm{C}$.

Desta forma, entende-se que a 'Coralina' apresenta maior amplitude de adaptação térmica que a 'Turmalina'. Quando cultivada em ambiente natural (temperatura média abaixo de $18^{\circ} \mathrm{C}$ ), a 'Coralina' não diferiu da produção em cultivo sob agrotêxtil. Por outro lado, a 'Turmalina', quando em temperaturas abaixo da citada por Filgueira (2000), não manifestou seu potencial produtivo. Esta apresentou aumento da produtividade quando cultivada sob agrotêxtil, devido possivelmente à exigência em temperaturas mais elevadas para crescimento e desenvolvimento.

A partir dos resultados obtidos, pode-se concluir que, visando a produção de vagens do tipo macarrão na região de Ponta Grossa durante o outono, a 'Coralina' é uma ótima opção por se adaptar às condições climáticas da região, não necessitando do uso de proteção. Por outro lado, quando se deseja a produção de vagens do tipo manteiga na mesma região, utilizando-se a 'Turmalina', o uso do agrotêxtil é excelente alternativa, pois essa cultivar apresentou consideráveis aumentos de produtividade neste tipo de cultivo, comparado-se com a produção em ambiente natural. Isto pode estar relacionado com o aumento da temperatura do solo e do ar sob o agrotêxtil em relação às condições naturais de cultivo.

Para as cultivares Turmalina e Coralina, o uso de baixa densidade de plantas $\left(3,3 \mathrm{pl} \mathrm{m}^{-1}\right)$ é mais viável economicamente, pois possibilita redução na quantidade de sementes e insumos, além de facilitar os tratos culturais. 


\section{LITERATURA CITADA}

ADSULE, R.N.; DESHPANDE, S.S.; SATHE, S.K. French bean. In: KADAM, S.S.; SALUNKHE, D.K. (editores). Handbook of vegetable science and technology: Production, composition, storage and processing. New York, 1998. p. 457-469.

ALMEIDA, T.C.; CANÉCHIO FILHO, V. Exigências climáticas. In: IAC. Principais culturas. 2 ed. Campinas, SP, 1974. p. 33-40.

ANDRADE, M.J.B. Clima e solo. In: VIEIRA, C.; PAULA JUNIOR, T.J.; BORÉM, A. Feijão: Aspectos gerais e cultura no estado de Minas. Viçosa: UFV, 1998. p. 83-97.

ARAÚJO, G.A.A. Preparo do solo e plantio. In: VIEIRA, C.; PAULA JUNIOR, T.J.; BORÉM, A (editores). Feijão: Aspectos gerais e cultura no estado de Minas. Viçosa: UFV, 1998. p. 99-122.

COLTURATO, A.B.; JACCOUD FILHO, D.S.; OTTO, R.F.; GASPERINI, L. Avaliação da ocorrência de Alternaria brassicae em couve-chinesa cultivada sob agrotêxtil e ambiente natural na região de Ponta Grossa - Paraná. Horticultura Brasileira, Brasília, v. 19, n. 2, suplemento CD-ROM 2001

DOURADO NETO, D.; FANCELLI, A. L. Produção de feijão. Guaíba: Agropecuária, 2000, 385 p. DRAKE, S.R.; SILBERNAGEL, M.J. The influence of irrigation and row spacing on the quality of processed snap beans. Journal of the American Society for Horticulture Science, v. 107, n.2, p. 239-242, 1982.

EMATER. Lançamento: feijão-vagem Turmalina e Coralina. (Folder). Goiânia, 1997.

FAOUZI, E.H.; CHOUKR, R.A.; HANDI, B.; REYD, G. Influence of nonwovens on growing winter courgetts in Southern Marroco. Plasticulture, v. 98, p. 31-40, 1993.
FILGUEIRA, F.A.R. Novo Manual de Olericultura: Agrotecnologia moderna na produção de hortaliças. Viçosa: UFV, 2000. p. 309-313. FUELLO, M.A.O.; BARANDA, A.A.; ARRIETA, A.I. Semiforzado de lechuga con agrotextiles - Producción de otoño-invierno al aire libre. Hortofruticultura, v. 4, p. 37-40, 1993.

LOLLATO, M.A. Efeito da população de plantas. In: IAPAR. Feijão: Tecnologia e Produção. Londrina: IAPAR, 2000. (Informe de pesquisa, 135), p. 25-36.

MARIOT, E.J. Aptidões climáticas, ideótipos e épocas de cultivo do feijoeiro no Paraná. In: IAPAR. Feijão: Tecnologia e Produção. Londrina: IAPAR, 2000. (Informe de pesquisa, 135) p. 5-13.

MANSOUR, N.S.; HEMPHIL, D.D. Bunching onion response to three floating row covers. HortScience, v. 22, n. 2, p. 318-319, 1987.

MERMIER, M.; REYD, G.; SIMON, J.C.; BOULARD, T.; The microclimate under agryl $\mathrm{P}$ 17 for growing lettuce. Plasticulture, v. 107, p. 4 $12,1995$.

MOURÃO, I.M.G.G. Utilização de filmes plásticos na cobertura direta de culturas olerícolas: I Efeitos no microclima. Revista de Ciências Agrárias. v. 20, n. 4, p. 37-61, 1997.

OLIVEIRA, A.P.; BRUNO, G.B.; PEIXOTO, N.; VALADARES, W.A.; TAVARES SOBRINHO, J.; ALVES, E.U. Avaliação de linhagens e cultivares de feijão-vagem arbustivas, nas condições de Areia-PB. Horticultura Brasileira, Brasília, v. 19, n. 2, suplemento CD-ROM, 2001.

OTTO, R.F.; REGHIN, M.Y.; TIMOTIO, P.C.; PEREIRA, A.V.; MADUREIRA, A. Eficiência do 'não tecido' de polipropileno na proteção contra danos de geada na cultura do morangueiro, no município de Ponta Grossa - PR. Horticultura Brasileira, Brasília, v. 18, suplemento, p. 208-209, 2000a.
OTTO, R.F.; REGHIN, M.Y.; TIMOTIO, P.C.; PEREIRA, A.V.; MADUREIRA, A. Resposta produtiva de duas cultivares de morango sob 'não tecido' de polipropileno no município de Ponta Grossa - PR. Horticultura Brasileira, Brasília, v.18, suplemento, p. 210-221, 2000b.

OTTO, R.F.; GIMENEZ, C.; CASTILLA, N. Modificações microclimáticas sob proteção de polipropileno cultivado com espécies hortícolas em Córdoba, Espanha. Horticultura Brasileira, Brasília, v. 18, n. 3, p. 204-211, 2000c.

OTTO, R.F.; REGHIN, M.Y.; SÁ, G.D. Utilização do 'não tecido' de polipropileno como proteção da cultura da alface durante o inverno de Ponta Grossa - PR. Horticultura Brasileira, Brasília, v. 19, n. 1, p. 49-52, 2001

PEIXOTO, N.; THUNG, M.D.T.; SILVA, L.O.; FARIAS, J.G.; OLIVEIRA, E.B.; BARBEDO, A.S.C.; SANTOS, G. Avaliação de cultivares arbustivas de feijão-vagem, em diferentes ambientes do Estado de Goiás. Goiânia: EMATER-GO, 1997. (Boletim de Pesquisa 01), 42 p.

PEREIRA, A.V.; OTTO, R.F.; REGHIN, M.Y. Efeito da proteção com agrotêxtil na produtividade da cultura do pimentão em Ponta Grossa - PR. Horticultura Brasileira, Brasília, v. 19, n. 2, suplemento CD-ROM, 2001.

REGHIN, M.Y.; OTTO, R.F.; SILVA, J.B.C. "Stimulate Mo" e proteção com "tecido não tecido" no pré-enraizamento de mudas de mandioquinha-salsa. Horticultura Brasileira, Brasília, v. 18, n. 1, p. 53-56, 2000.

SILVA, C.C. Estabelecimento da cultura. In: ARAÚJO, R.S.; RAVA, C.A.; STONE, L.F.; ZIMMERMANN, M.J.O. Cultura do feijoeiro comum no Brasil. Piracicaba: Potafós, 1996. p. 417-428. 